\title{
Editor's Introduction: The Psychotherapy Case of "Sharon"-A Comparative Analysis Using Contrasting Interpersonal Theories
}

\author{
DANIEL B. FISHMAN ${ }^{\mathrm{a}, \mathrm{b}}$ \\ ${ }^{\text {a }}$ Graduate School of Applied and Professional Psychology, Rutgers University-New Brunswick, NJ \\ ${ }^{\mathrm{b}}$ Correspondence regarding this article should be sent to: Daniel B. Fishman, 43 Clarewood Lane, Oakland, CA \\ 94618. \\ Email: dfishman.rutgers@gmail.com
}

\begin{abstract}
This article is a brief orientation to the current PCSP issue, which presents and compares two contrasting, interpersonal theories - Interpersonal Defense Theory and Interpersonal Reconstructive Therapy - for developing a case formulation and treatment plan for the case of "Sharon," a 28-year, unmarried social worker with no children. At the beginning of Sharon's therapy, which was part of a randomized clinical trial (RCT), Sharon presented with comorbid anxiety and personality disorders. A major focus of her problems was being stuck between being simultaneously drawn to and repelled by "Jeff," her former finance. In reading this article series, a number of important themes to keep in mind are mentioned, including (a) comparing theoretical similarities and differences between the two theories; (b) the differences in the information selected by each theory from the large database of quantitative and qualitative clinical information in the database generated by the RCT; and (c) the enrichment of theory that occurs when it is applied to an individual case.
\end{abstract}

Keywords: Interpersonal Defense Theory; Interpersonal Reconstructive Therapy (IRT); case formulation; treatment planning; comparing therapy approaches; case studies as theory enrichment; case study; clinical case study

\section{ORIENTATION TO THIS PCSP ISSUE}

At the time she sought therapy, Sharon was a 28 -year-old unmarried white female with no children who worked as an MSW social worker with disadvantaged children. Sharon suffered from an anxiety disorder with accompanying concentration and procrastination difficulties together with psychological patterns that later led to her being diagnosed with a personality disorder having avoidant, self-defeating, and paranoid components.

A focus of Sharon's problems was her relationship with "Jeff." The two had been in a relationship for $5 \frac{1}{2}$ years and then had gotten engaged. Sharon then called off the wedding because Jeff refused to go to couples therapy to work on problems in their relationship, such as his temper. Sharon entered individual therapy and was intensely stuck, saying on one hand that she wanted to get over her relationship with Jeff, but on the other hand that she still loved him. 
The central importance of this issue for Sharon ... was reflected in the fact that the first two of her Target Complaints were (1) "guilt and agony" about her broken engagement with Jeff, an engagement she had ended roughly one and a half years before beginning treatment, and (2) "difficulty moving on and leaving the past behind" (Westerman \& Critchfield, 2021a).

Sharon's presenting comorbid anxiety and personality disorder problems qualified her to receive psychotherapy in a randomized clinical trial (RCT) for such cases (Muran, Safran, Samstag, \& Winston , 2005). The RCT compared three treatments, all at a fixed length of 30 weekly sessions: short-term dynamic therapy (called "Brief Adaptive Psychotherapy" or BAP); cognitive-behavioral therapy; and brief relational therapy). Sharon was randomly assigned to the BAP treatment.

All three treatment conditions were found to be effective, and equally so, but Sharon's therapy was deemed a poor outcome based on specific pre-established criteria for such a result. Specifically, she showed clinically significant improvement on only one of six outcome measures employed in the study. These six included patient and therapist ratings of Target Complaints; therapist assessments on the Global Assessment Scale; and patient reports on the Symptom Checklist-90-Revised, the Inventory of Interpersonal Problems-64, and the Wisconsin Personality Disorder Inventory (see the second article in this issue [Westerman \& Critchfield, 2021a] and Muran et al., 2005 for more details on these measures).

The focus of this issue of PCSP is to analyze in depth why Sharon's BAP therapy, a therapy which overall had shown treatment effectiveness, was unsuccessful for her. Such an analysis is possible because the design of this RCT, as in all properly designed RCTs, yielded a great deal of quantitative and qualitative data, including, among others, the six before-and-aftertherapy measures mentioned above and videotapes of all the psychotherapy sessions. This wealth of data allows for a research design called the "Case Studies Within Psychotherapy Trials" model, or, for short, the "Case Within Trials" model for short (see Fishman, Messer, Edwards, \& Dattilio, 2017). In this research design, good-outcome and/or poor-outcome cases can be determined from the quantitative group results; and these individuals' therapies can then be retrospectively recreated and then qualitatively analyzed from the videotapes of the original therapy, in the context of each case's quantitative results. The resulting qualitative case studies provide knowledge that is complementary to the quantitative group results of the RCT, e.g., identifying why a patient like Sharon had a poor outcome, even though she received treatment in an RCT condition that was found to be empirically effective.

The project in the present issue is a creative, complex application of the Cases Within Trials model. Specifically, in the project two different researchers each apply a related but contrasting interpersonal psychotherapy theory to provide a distinctive case formulation and treatment plan for Sharon that is an alternative to those in the BAP therapy. By doing so, within their distinctive theories, each researcher explains, using their case formulation and treatment plan for Sharon, both why Sharon's BAP therapy was not successful and why a treatment based on their theory could lead to a successful therapy for Sharon. The two theories are Interpersonal Defense Theory (e.g., Westerman, 2019), put forward by Michael Westerman (2021a); and Interpersonal Reconstructive Theory (IRT; e.g., Benjamin, 2018), put forward by Kenneth Critchfield, Julia Dobner-Pereira, and Eliza Stucker (2021a). 
As can be seen from the present issue's Table of Contents, to encompass an analysis of the Case of Sharon from two different theoretical points of view as described above, the structure of this issue is divided into four pairs of articles: (a) two articles that present an introduction to and background of the project; (b) two articles that present the contrasting theoretical analyses of the Case of Sharon, based on Interpersonal Defense Theory, on the one hand, and IRT, on the other; (c) two articles in which the author(s) of each theory compare their approach with the other one; and (d) two articles in which an outside expert commentator (Stanley Messer, 2021) discusses the broad implications of the project followed by a response from the two primary authors.

\section{SOME THEMES TO KEEP IN MIND}

One theme that runs throughout the issue is the extent to which the two theoriesInterpersonal Defense Theory and IRT — are similar to, complementary to, and contrasting with each other. For example, on one hand both theories focus on interpersonal dynamics, resonate with psychodynamic concepts, and employ Benjamin's (1979) Structural Analysis of Social Behavior (SASB) as a conceptual framework. On the other hand, the two theories differ in how they address these various conceptual areas.

A related theme concerns differences between the theories concerning which information from the large clinical database about Sharon - quantitative questionnaires, videotapes, etc.each theory draws upon. Since each theory selects certain data to focus on, and since these data are different, it is not possible to ask which theory is the most accurate description of the reality reflected by all the data. However, the last two articles in the series particularly explore how it is possible to compare the value and validity of the theories in a variety of ways, e.g., by their theoretical persuasiveness, by their ability to generate effective therapy, and by their ability to predict new data not covered in their original case formulation and treatment plans.

Finally, a broad theme running throughout this article series is the process by which applying theories to an individual case actually expands the substantive meaning of general theoretical concepts by concretizing them with specific, contextually embedded, narratively structured examples of case material. On this topic, Messer (2011) writes:

There is an interplay between the propositions of the theory and the facts on the ground; each informs and alters the other. This can be described by what is known as the hermeneutic circle wherein the parts of a theory take meaning from the individual statements and these derive their meaning from the whole. Similarly, there is a reciprocal relationship between clinical observations and the theory within which the practitioner operates, each informing and giving meaning to the other. For the psychotherapist, a theory is not merely an abstract device or an object of elegance and beauty, but is a way to think concretely about clinical cases (p. 440).

I direct the reader to pay attention to this process as Westerman and Critchfield et al. set forth the general tenets of Interpersonal Defense Theory and IRT, and then employ the case of Sharon to enrich both of these theories and the comparison of them. 


\section{REFERENCES}

Benjamin, L. S. (1979). Structural analysis of differentiation failure. Psychiatry: Journal for the study of interpersonal processes, 42, 1-23.

Benjamin, L. S. (2018). Interpersonal reconstructive therapy for anger, anxiety, and depression: It's about broken hearts, not broken brains. Washington, DC: American Psychological Association.

Critchfield, K.L., Dobner-Pereira, J., \& Stucker, E. (2021a). The case of Sharon considered from the vantage point of Interpersonal Reconstructive Therapy. Pragmatic Case Studies in Psychotherapy, 17 (1), Article 4, 42-62. Available: http://pcsp.libraries.rutgers.edu/

Fishman, D.B, Messer, S.B., Edwards, D.J.A., \& Dattilio, F.M. (2017). Case studies within psychotherapy trials: Integrating Qualitative and quantitative methods. New York: Oxford.

Messer, S.B. (2011). Theory development via single cases: A case study of the therapeutic relationship in psychodynamic therapy. Pragmatic Case Studies in Psychotherapy, 7(4), Article 2, 440-448. Available: http://pcsp.libraries.rutgers.edu/

Messer, S.B. (2021). How do we decide which of two case formulations is correct? Commentary on Westerman and Critchfield et al. Pragmatic Case Studies in Psychotherapy, 17 (1), Article 7, 104-108. Available: http://pcsp.libraries.rutgers.edu/

Muran, J. C., Safran, J. D., Samstag, L. W., \& Winston, A. (2005). Evaluating an alliancefocused treatment for personality disorders. Psychotherapy, 42, 532-545.

Westerman, M. A. (2019). Case formulation in interpersonal defense theory: A process model of interpersonal phenomena that play key roles in psychopathology and psychotherapy. In U. Kramer (Ed.), Case formulation for personality disorders: Tailoring psychotherapy to the individual client (pp. 315-335). London, United Kingdom: Elsevier.

Westerman, M.A. (2021a). The case of Sharon considered from the vantage point of Interpersonal Defense Theory. Pragmatic Case Studies in Psychotherapy, 17 (1), Article 3, 19-41. Available: http://pcsp.libraries.rutgers.edu/

Westerman, M.A., \& Critchfield, K.L. (2021a). Goals and design of the project and basic information about Sharon's case. Pragmatic Case Studies in Psychotherapy, 17 (1), Article 2, 5-18. Available: http://pcsp.libraries.rutgers.edu/ 